\title{
Gender Identity
}

Maria Patrícia Ribeiro

Magalhães Lemos Hospital

\author{
Diana Moreira \\ University of Porto \\ Maia University Institute \\ Rui Coelho \\ University of Porto \\ Altamiro Pereira \\ University of Porto \\ Fernando Almeida \\ University of Porto \\ Maia University Institute
}

\begin{abstract}
AUTHOR NOTE
Maria Patrícia Ribeiro, Magalhães Lemos Hospital (Portugal). Diana Moreira, Laboratory of Neuropsychophysiology, Faculty of Psychology and Educational Sciences, University of Porto, Social and Behavioral Sciences Department, Maia University Institute, and Portucalense Institute of Neuropsychology and Cognitive and Behavioral Neurosciences (Portugal). Fernando Almeida, Social and Behavioral Sciences Department, Maia University Institute and Instituto de Ciências Biomédicas Abel Salazar, University of Porto (Portugal).
\end{abstract}

The authors do not have financial, personal, or professional conflicts of interests. The study was conducted according to APA ethical standards.

The authors would like to express their deepest appreciation to Professor Amílcar Augusto for his held dear input and encouragement.

\begin{abstract}
The aim was to contribute to future research on Gender Identity associated with other domains of human reality, while looking to not forget that, over time, it was an essential topic in Arts and Sciences, reflecting a curiosity to define, interpret, and research "representations" of masculine and feminine roles regarding the "actors" (men or women) of the "acts", as well as their "spectators" (the other men and women, who are all of us). Currently, there seems to be an intensifying of undifferentiation of the roles assigned to Gender, a kind of androgyny, though without this meaning the existence of internal resonance of this undifferentiation, as if one walked towards a narcissistic society, as if it were mental hermaphroditism.
\end{abstract}

Keywords: gender identity, gender, sex roles, development, systems of observation/analysis 


\section{GENDER IDENTITY}

The various studies and literature reviews, consultation of databases, expert discussions, and theoretical syntheses on the issue have inspired mankind to conceive developmental and evolutionary theories, as well as maps for the exploration and assessment of gender identity (GI). If each evaluation (tests, scales, inventories) symbolizes facets of this construct, organizing them as a guide to the study of its concepts and dimensions, we would need different evaluations for different purposes and stages of this work. Which evaluation system is more isomorphic with the format of the territory and what results would it emphasize or minimize?

The approach taken by many authors characterizes the evidence of several gender differences, especially in terms of social and sexual behavior, personality traits, and physical or cognitive abilities. Many other authors, however, would argue that gender does not have predictive value (or has it inaccurately), compared to other factors, and accentuates the differences between the sexes, thus, it would have us question the legitimacy of maintaining and justifying the existence of separate universes for men and women.

To this review of an entire constellation of theoretical/practical or categorical/dimensional systems, we would systematically add some concepts inspired by clinical practice. We would like to focus on the knowledge regarding GI, stripping it to its various components, without cultivating gender differences or advocating for the valorization/exclusion of its evaluative systems.

The purpose of such pretensions would be to reveal the intra and interrelational stages of communication in terms of personality/sexuality, with their theories of development and evolution, possibly contributing to the progress of scientific knowledge on psychosexual structuring along the pathological vs. normative continuum.

\section{CONCEPTS AND DEFINITIONS}

The Diagnostic and Statistical Manual of Mental Disorders (APA, 2013) describes Gender Identity (GI) Disorders by characterizing them as crossed, intense and permanent Gender Identification, accompanied by persistent discomfort with the sex assigned to them; Gender Dysphoria as an intense and persistent feeling of ill-being toward the sex assigned to the individual, the desire to possess the body of the other sex and the desire for others to consider the individual as a member of the opposite sex; specifiers based on the sexual orientation of the individual: (a) sexually attracted to men; (b) sexually attracted to women; (c) sexually attracted to both; (d) sexually attracted to none.

After all, what is GI? The term gender, often used as a synonym for sex, indicates the physical polarity of anatomy, used to differentiate between male and female. Thus, gender would be the recognition of the masculine and feminine characteristics of a person. In Sociology, according to Stöller (1984), GI would describe the gender with which a person identifies, or conceives themselves as being a man, or a woman, but would also refer to the gender that other people would assign to the individual, based on what they knew as indicators of gender roles (e.g., clothes, hairstyle).

Accordingly, GI would start with the perception that one belongs to one sex and not the other, carrying the conviction that the assignment of their sex had been correct.

The term gender role used in Social and Humanitarian Sciences would highlight behavioral norms that would accompany a certain gender status (or identity) in a certain social system or 
group, and would have two meanings which, in individual cases, could be divergent, such as: (a) the totality of ways through which people express their gender identities; (b) the forms of activities that society deems appropriate for individuals with their type of external genitalia. Therefore, men would differ from women in a variety of behaviors and stereotypes that would not be real for all people.

Egan and Perry (2001) defined gender as an essential element of human identity. Gender characterization would normally be unchanging, and its aspects (academic, occupational, recreational, and relational) would be governed by gender. GI would be: (a) recognition as a member of a gender category; (b) feeling of compatibility with their gender group (selfperception of gender-typing and feelings of satisfaction with their own gender); (c) feeling of pressure to conform to gender; (d) attitudes directed to the gender group.

Bem (1981), Harris (1995), and Maccoby (1998) would conceive GI as a construct in several approaches of psychosocial development and mental health. Bem (1981) would view GI as the degree to which each individual internalizes the social pressures for Gender conformity. For Kohlberg (1966), GI would be the knowledge that one is more a member of one sex than the other. Kagan (1964) would define it as the degree to which each individual perceives the self in conformity with the cultural stereotypes of their gender, whereas Green (1974) and Rekers $(1972,1975,1977)$ would conceive it as a fundamental sense of acceptance of belonging to a gender. Stöller (1968) and Green (1974) would define the concept of GI as a basic feeling that each person would have of themselves, of masculinity or femininity, acquired early and relatively invulnerable to change. Yarhouse (2001), in accordance with Althof (2000), would differentiate the concept of GI from SI as a fundamentally sexual substructure that includes: GI ("feeling of being masculine of feminine"), object-choice ("multiple sources of choice of personal attraction - who, or what the person discovers to be sexually stimulating"), and intention ("what each individual wishes to do with their sexual impulse") (Yarhouse, 2001, p. 331). Gender could be the biological or social characteristics that influence people to define male and female and gender role as a series of behavior norms for male and female. In regard to GI, although boys and girls differ in their physical, intellectual, and emotional development, there is no evidence that these differences remain thusly associated. It is unlikely that educational performance is explained by biological differences.

Freund, Steiner, and Chan (1982), on cross GI, would define it as a fantasy believed to be true, intermittent and virtually being a person of the opposite sex. If heterosexuality is the preference for people of the opposite sex, homosexuality is the preference for people of the same sex, when there is free choice of partner, not only for their sex (term that would denote a masculine or feminine type from visible external somatic characters), but also for other attributes that co-determine erotic attraction.

The terms homo and heterosexuality would only evidence an erotic preference for the body and form and not for the type of sexual behavior. Therefore, a male could erotically prefer the body of a female (be heterosexual) and at the same time have a male-type behavioral preference in their partner, or have female-type attitudinal components in their own sexual behavior. Of bisexuality they would say that the greater the erotic preference for the body form of one sex over the other, the lower the degree of bisexuality (Freund et al., 1982, p. 50). The highest index of bisexuality would be achieved when there was no difference between erotic responses to the body form of females and males. Angelides (2001) refers to bisexuality as a true foundation upon which the notions of hetero/homosexuality (binary logical systems within themselves) are constructed. Bisexuality would be a movement based on identity and 
imperative for the construction of sexuality (and potentially other dichotomies such as gender).

\section{DEVELOPMENT AND EVOLUTION}

Psychoanalysis. According to Psychoanalytic Theory, the development processes of the Oedipal Period would be crucial in the establishment of GI. We would synthesize from the legacy of Freud $(1905,1908,1915,1917,1923)$ direct or indirect references to the concept of GI, specifically to Masculinity/Femininity. In the original matrix of this theory, boys and girls would initially be masculine in the functioning of anatomical structure. Boys would be male in embryonic origin and anatomical structure. Girls would be anatomically bisexual (only the clitoris, an anatomical remnant of the male organ, would be important in their early development, in relation to the female vagina). During the first years of life, libidinal orientation would be masculine in both sexes. The development of boys would thus be directionally masculine. They would identify with their father and would accept his values, cementing their masculine identity. For girls, the central step would be the acquisition of a feminine GI and heterosexual orientation, on the basis that they would be male in their clitoral focus, masculine in their instinctive orientation, and homosexual in their primary object relation. With the knowledge that their sexual organ would not be as large as the boys', or would not exist, they would distance themselves from their mother in rage and disappointment, and would substitute the desire to have a penis with the desire to have a baby from their father, taking the greatest step from homosexual orientation to heterosexual orientation, cementing their feminine identity.

The notion that girls would be masculine in GI during the first years of life would not be consolidated, nor necessarily refuted. Like Stöller $(1968,1975)$, we adopt the terms male and female for biological themes, and masculine and feminine for themes of psychological nature. Fraiberg (1972), Kestenber (1968), Barnet (1960), and Torok (1979) considered the issue that girls have early knowledge of the vagina. The conception that the earliest matrix of the development of GI is unequivocally male and masculine was also questioned. Stöller (1968) argued that physiological factors have an appreciable, but secondary, influence on GI. Thus, one of the major social factors for boys and girls would be their early identification with their mothers and, later, uncertainty of their primary sense of masculine identity, an idea also corroborated by Greenson (1968). More than male and masculine in their primary gender orientation, children would be inconclusive regarding their sexual differences, or their knowledge of the limitations inherent to belonging to a certain sex. By considering notions of such bisexual completeness in themselves and attributing them to others (Bégoin, 2000), they would walk toward their own SI. With respect to feminine GI, contemporary theories would differ from Freud (1920), fundamentally: (a) femininity would be achieved through masculinity; (b) penis envy would be a necessary evolutionary step for every woman; (c) the desire to have a child would always be a substitution of the phallus; (d) a woman's aggressiveness and competence would always derive from unconscious penis envy and the desire for castration; (e) passivity and masochism would be predictable character traits of femininity.

Bisexuality would thus be a fundamental element in gender identification and personal identity and in heterosexual life. The occurrence of bisexual figures in primitive and mythological art would be summarized by Freud (1905) with conceptualizations of: biological or constitutional bisexuality linked to embryonic remnants and the synergy of androgenic and estrogenic hormones and psychological bisexuality (coexistence within the same human being of masculine and feminine traits), influencing their choice of object, as well as their entire personality). 
David (1975), Kubie (1974), and Bettelheim (1954) would focus on the occurrence of the desire in men and women to add attributes of the other sex to their own attributes, so that in all individuals there would be an unconscious instinct that would not be given by the gender in which one is born, but rather to complement it, developing itself side-by-side with the opposite gender and ending in both. Stöller (1968), studying the relationship between impulses and their sexual orientation, would not be concerned with the norm and the adequate, but with verifying whether the impulse experienced in and by the individual was adequate or not with their sense of identity, or in the case of GI, would not be confused with the identity of being. Evolutionarily, bisexuality would emerge as a sexuality through the establishment of Freudian ideas in which: (a) the choice of sexual object would be defined by gender; (b) one would not be able to desire more than one object of gender in a particular time period.

From the Theory of Identity Development by Erikson (1968), we emphasize that welldeveloped identities would become stable, with a persistent similarity with the Self and would share some type of essential character with Others. Multiple potential hazards (e.g., failure of the parents to provide a model of Oedipal identification) would exist from the outset (Silverman, 1986), causing the regression to pre-oedipal narcissistic patterns. The determining role of parental actions of sexualization in the development of SI would be focused through the process of identification with the parent of the same sex (Biller, 1976; Chodorow, 1974; Douvan, 1960; Lynn, 1976), or would concentrate itself in identifying characteristics of the parental model that would promote the child's imitation (Bronson, 1959; Hetherington, 1965; Moulton, Liberty, Burnstein, \& Altucher, 1966). The later tendency (Heilbrun, 1976; Kelly \& Worell, 1976; Orlofsky, 1979; Pleck, 1975; Spence \& Helmreich, 1978; White \& Speisman, 1977) would be to acknowledge the influence of both parents in the formation of SI. Thus, psychosocial identity would be a sense of being at home in one's own body, knowing where one is going, and having the intimate certainty of anticipated recognition by significant others. True commitment to others would be the result and the proof of a firm self-definition, while the latent fragility of identity would sometimes reveal itself in mutual narcissistic reflexes (Rouart, 1975). The loss of the sense of identity would frequently be expressed by disdainful hostility regarding the roles offered to them as appropriate and desirable within the family and community (such as masculinity; femininity; nationality; class membership). In turn, the polarization of sexual differences would entail the elaboration of their particular proportion of masculinity and femininity in harmony with the development of identity (Erikson, 1968). Indeed, bisexual confusion in adolescence would be added to identity consciousness, expressed in the question: what type of man or woman, half-term or deviation, could the individual become? We would answer with Rosenfeld (1971, p. 171):

"One chooses an object of the same sex, by virtue of one's own internal difference in viewing that sex. Visible identity covers an invisible otherness. One chooses an object of the other sex, also by virtue of one's own difference, here both anatomical and psychological, but this choice cannot hide latent homosexuality, since there is always a certain degree of dissatisfaction".

Anthropology. Jung (1959, 1971) would conceptualize, in anthropological terms, two complementary principles that would influence behavior: (a) one Feminine - Eros and (b) one Masculine - Logos. The former would express a tendency toward relationships with others. The latter would reveal characteristics such as logic and rationality.

Sociology/Social Psychology. Campo, Nijman, Merckelbach, and Evers (2003) argued that girls experience puberty before boys, feeling more pressure to explore adult roles, accompanying the maturity of their own bodies, acquiring the identity before them. It is possible to conclude that individuals in general need environmental support for evolutionary 
liberation of different identities, promoting individuality and interrelation. On the other hand, Grotevant (1992) hypothesized that adopting a socially undervalued identity would lead to psychological disorders, such as feelings of inferiority, reduced self-esteem, and external locus of control, as well as social discrimination, which would inhibit identity development. Thus, compartmentalization in the development of SI would facilitate the development of the identity of individuals in other domains.

For a long time, masculinity seemed to, indeed, have unquestionable evidence. SI would supposedly belong to nature itself. Referring back to the Aristotelian adage: "It is men who generate men". According to Badinter (1992), they would have been saved from an entire work of differentiation and opposition, which would indelibly mark the masculine fate. The father/mother could ease the pains of separation and facilitate the acquisition of masculine identity, but could not override the effects of the original fusion. Nineteenth century literature would represent the Androgyne as an effeminate, bisexual young person, a non-sexual being or virgin adolescent that, once succumbed to women and the first affirmation of sex, would resolve themselves in male and feminine. Thus, one would not be born a man but would become one and only then would one be able to find the other and aspire to androgyny, which would characterize the reconciled and complete man, with acceptance of a feared femininity and the invention of a masculinity compatible with it.

Would there be a possibility of a developmental route directed toward bisexual identity? Yarhouse (2001, p. 335) would relate bisexuality and homosexual identification, in which the former could belong to a stage prior to the latter. Current models of longitudinal development (early, middle, and late adolescence) of bisexual identity: "(a) First sexual opposition in attraction, behavior and relationships; (b) First attraction for the same sex in behaviors and relationships; (c) First identification of the Self as Bisexual; (d) Openness of the Self to the Sexual Identity".

Cass (1979) would develop the gay and lesbian identity in six stages, concluding that these personal identifications would be part of what they feel to be: (a) Identity Confusion; (b) Identity Comparison; (c) Identity Tolerance; (d) Identity Acceptance; (e) Identity Pride; (f) Identity Synthesis".

Coleman (1982) would describe a process of five stages in simultaneous with the emergence of experience: (a) $1^{\text {st }}$ Stage - Pre-coming out: process of preconscious awareness of the identity of the same sex; $2^{\text {nd }}$ Stage - Coming out: homosexuals begin to make peace with their sexuality, consenting to tell others what they feel; $3^{\text {rd }}$ Stage - Exploration: homosexuals explore and experience a new SI, getting involved in more sexual contacts and social work with gay or lesbian communities; $4^{\text {th }}$ Stage - First Relationships: re-conceptualization of themselves as people able to love and be loved, be eligible for a new relationship; $5^{\text {th }}$ Stage - final Integration: gays and lesbians are now able to maintain a longer relational commitment.

There would be a continuum of heterosexual, bisexual, homosexual identities, not as distinct categories, but rather integrated in a sequence of sexual attraction, suggesting a possible plasticity of feelings, behaviors, and sexual identification.

Queer Studies. Sexual and gender identities would be socially constructed in a partial or total way, and individuals should not be compartmentalized as homosexual or women. Queer Theory would include in its historical influences Jacques Lacan, Louis Althusser, and Jacques Derrida, with initial prominence for Michel Foucault. According to Foucault (and Simone de Beauvoir), gender would not be related to sex. An individual would be born with masculine 
genitalia, but would continue to be of the feminine gender. During the 80 s, there would be growth of the idea that the sex one is born with would not directly determine each person's abilities (Foucault, 1994).

The masculine gender role would become more malleable, containing more typically feminine empathy associated with emotional responses, and a metrosexual would be a male who would adopt habits associated with females. Considering these products of inversability of nature, the simple picture in its original appearance, with a high degree of consistency between external genitalia, GI and gender role, would dissolve itself into a sort of puzzle that is hard to assemble correctly. The extra parts of this puzzle would fall into two hermetic categories: Non-typed GI and Non-typed Gender Roles.

During the 60s and 70s, there would be development of a series of deconstruction work focusing on homosexuality as an identity, an ethnic-minority model of assimilation and legitimization. According to Foucault (1994), the structuring of sexuality should follow the resistance of the pathologizing heterosexual normative dynamics.

Both approaches would seem to fail in their ability to "deconstruct" sexuality: the assimilation model for its ignorance in the articulation of the sexual categories derived from the models of evolution of primitive Bisexuality, and the Foucault model due to its ignorance concerning the notion of the male of modern Self.

As Angelides (2001) would argue, without bisexuality, the categories of sexuality could only be rearranged or renamed. With bisexuality, there would be a reversal in the hierarchy that could not be restricted to the discourse of Social Sciences environments, but included in all sectors of Science and popular media, acknowledging it as a destabilizing force. We would benefit from new interpretations of these topics, communicating the love for exploration, without being imprisoned in theories.

Biology. Growing physiological, genetic, and sociological fields would evidence that sexual orientation and classification would be more than just simple social constructs. Several biological characteristics (some hereditary) would represent an important role in shaping sexual behavior. Many scientists would argue that this deconstructionism would be pseudoscience and others would respond that not all individuals would be clearly classified as male and female even on a strictly biological basis. This would complicate the use of genotype to define both genders as distinct, in which intersexual individuals could, for many different biological reasons, have ambiguous genitalia. Therefore, the issue of innate sexual and gender identity would be excluded with the argument that GI would be a personal social construct. Biological aspects would not be as relevant for those who see the construction process play out within natural language, with the formation of categories in mental efforts - pronouns, for example, which would create formal or gender distinctions. Jacques Lacan (1966), in a psychological model, would argue that it could be language that would construct the idea of Self, as well as also sexual and gender distinctions (e.g., the mirror phase in which the child would believe in their own image as being themselves and the development of language would occur simultaneously).

Hybrid theories would combine innate characteristics and social constructs, in which customs, social expectations, and identities would be shaped by certain life factors, which would include innate structures, from the obvious (e.g., differences between reproductive organs) to the controversial (e.g., a sexual orientation established in early phases by genetic and external 
environmental factors). The role of Queer Theory would examine the biological notions of sexual orientation and gender in the context of culture and history.

Gangestad, Bailey, and Martin (2000), regarding the Neuro-Hormonal Theory, would reveal that the pre-natal pathologies of hormonal processes, which would also affect other morphological and behavioral differences, would be the main reasons for homosexual sexual orientation, atypical gender identity in adulthood, and atypical pathology of sex in childhood, resulting in their covariance. In conclusion, the formation of non-sex-typing in early hormonal processes conjectured by this theory of sexual orientation seemed necessary, but not sufficient for the development of homosexual orientation. Most likely, this orientation would not reflect so much a non-sex-typed evolutionary change, but rather the failure to channel the sex-typed sexual orientation. The existence of an underlying rate in the development of sexual orientation and GI would argue against simply additive models of causality (several independent events would affect it, each with small reflexes).

Science. Nosek, Banaji, and Greenwald (2002) focused on the fundamental dichotomy of gender as they researched preference for Mathematics (and Science) vs. Arte (and Language). The covariance between gender and orientation for Mathematics and Science demonstrated that men would assume to be more inclined and very good in Mathematics and Science, compared to women (National Science Foundation [NSF], 1996).

A masculine or feminine member would be induced to non-preferential options and differences, seeming to be an individual and free goal in a self-imposed system of social segregation. Four types of associations relevant to the study of gender and orientation for Mathematics would be highlighted: (a) the association between the concept Mathematics and Evaluation (Good-Bad - Mathematical Attitude); (b) the association between Mathematics and Self (Mathematical Identity); (c) the association between Mathematics and Gender (Masculinity/Femininity - Mathematics/Gender Stereotype); and (d) the association between Self and Gender (GI; Nosek et al., 2002). In conclusion, members of feminine and masculine groups and the strength of identity with these groups would be related to preferences for: Mathematics, Mathematical Identity and Gender Stereotypes and Mathematics. Similarly to gender stereotypes, the strength of the belief that Mathematics would be linked to masculinity could deter the attitudinal impulses of women towards Mathematics, just as negative attitudes towards mathematics could increase the strength of gender stereotypes of Mathematics. An innate fundamental categorization into masculine and feminine groups would reflect an identification with their own social group, which in turn would be shaped and would shape experiences. Wanting, choosing, and liking would not be independent from social learning, limited by the solicitations of the social identity of the group and by gender stereotypes.

Disorders. According to the DSM-IV (APA, 2013), the diagnosis of GI disorder would emerge during a process of clinical interview, which would be "subjective and associated with experiences such as thoughts, feelings and impulses" (Bower, 2001, p.1). The symptoms of the transsexual adolescent would only be associated with occasional masturbatory activities and fantasies of sexual contact with people of the same sex, viewed by them as a heterosexual scenario. The following would be considered abnormal components for this diagnosis: (a) persistent identification with the opposite sex and (b) evident discomfort with their own sex. Two criteria would later be added: (a) absence of physical concordance of intersexual condition and (b) significant difficulty of integration in areas of social, occupational functioning or other types. It would also be pointed out in the DSM-IV (APA, 2013) that males with GI disorder would include the other specifiers: (1 - Attraction to males; 2 - Attraction to females; 3 - Attraction to both sexes; 4 - Attraction to none of the sexes), whereas females would be 
attracted to females. As associated factors, the focus would be on the symptoms during adolescence, especially in males, such as social isolation even in adulthood and, often, anxiety, depressive syndrome and personality disorders, emanated from parental and social pressures in the evolution of the individual's gender disorder.

Therefore, the etiology of GI disorders would remain an enigma, and the interaction between genetic, hormonal, and psychodynamic factors may coexist.

Davis (1998) would associate cultural considerations of SI and GI in the DSM-IV, which, in an initial reading, would reveal few sources with relevant criteria for the construction of SI and GI disorders, with apparent lack of sensibility for these issues. Initial constructs would be made for each of the three types of Disorders (Paraphilias, Sexual Dysfunctions, and GI). About GI: "Standardizations for sexual competence, as well as the nature and expression of sexual orientation, may be strongly influenced by cultural context which is markedly different from Western Society" (Davis, 1998, p. 403). Taking into account cultural factors for reasons related to the fact that sexual dysfunctions would be reduced to an individual biological sexual instinct, it would be a product of a historical process in western biomedical thinking, and the clinical judgment of the defenders of the DSM, as a facilitator of cultural sensibility, would in itself be an example of the tendency to reduce all mental disorders to biological causes.

Cultural constructionist criticism would be employed to change the biological essentialism of this group of disorders. In this tradition, love and sex are connected and sexual objectives are separate from fertility or reproduction, and what is good for men is good for women, for all ethnic groups and social classes. Some feminists would take advantage of biological reductionism, genital focus, mechanical image and objectified judgments (such as the orgasm), emphasizing the involvement of the Ego on sexual performance, which would characterize this category of Disorder (Irvine, 1995; Tiefer, 1995). Apparently, there would be no place in the DSM (with respect to women) for the inability to relax and the attraction to another partner that was not only interested in an orgasm. Davis (1998) would argue that feminine criticism would evidence the important route in which gender would be interpreted with culture.

Anderson and Cyranowiski (1995), regarding the role of personality in feminine sexuality, would conclude that emotionally positive characteristics (Extroversion) would favor sexual interactions, as opposed to negative ones (Neuroticism).

Klonsky, Serrita, Turkheimer, and Oltmanns (2002), relating personality disorders and GI, concluded that both men and women with more gender-typed behavior would exhibit more narcissistic and histrionic traits, whereas Rienzi, Forquera, and Hitchock (1995) would find no significant differences in the gender stereotypy in depressive and negativist personalities.

Campo et al. (2003), on the other hand, would focus psychiatric comorbidity of GI disorders, in particular with the following disorders: personality, mood, dissociative, and psychotic. In about half the cases, confusion with the other sex would be seen as an epiphenomenon or another disease. Therefore, the current criteria for GI Disorder in the DSM-IV would is not sufficient, since other pathologies explain the opposite-gender symptoms and should be excluded prior to that diagnosis. Regarding the development of SI in the context of compulsive heterosexuality, Konik and Stewart (2004) concluded that a minority SI (lesbian, gay, bisexual, or other nonheterosexual identity), with sexual and physical preference for the same sex, would be linked to greater global, political, religious, and occupational developmental advancement. 
O'Heron and Orlofsky (1990), regarding sexual roles, traits, and behaviors and their orientations, would argue that individuals who fail to develop traditional characteristics of their sex, or develop traits appropriate for the other sex, would suffer from an insecure or confused GI, and would have marked difficulties in their personality and integration in life. Bem (1975), Pleck (1977), and Spence (1984 a, b) would argue against this position, suggesting that some evolutionary deviations of orientation and androgynous behaviors (both in men and women) would not interfere with the development of GI, possibly even being beneficial for individual adaptation and integration. It would be undifferentiated men and women who would exhibit difficulties in their adjustment: females would exhibit higher levels of social anxiety, whereas males would reveal more generalized anxiety, feeling less masculine and adequate than other men. Thus, the influences in the orientations of sex-typed or non-sextyped roles would differ from men to women. There is little evidence that women who deviate from the sex role stereotype suffer from GI disorders or poor adjustment. Rubinstein (2003) would reveal that homophobic attitudes (defined as fear or hatred experienced towards homosexuals) (Weinberg, 1972), in which internalized instrumental traits are stereotypically associated with men, would involve repressive emotions as a sign of strength and nonvulnerability associated with masculinity. Klein (1993), however, had identified homophobic attitudes among bodybuilders, which would take the form of attacks towards male homosexuals in gymnasiums and hypersensibility to male prostitution. These individuals would exhibit four personality traits: narcissism, homophobia, hypermasculinity, and fascism.

\section{EVALUATION}

Terman and Miles (1936) would assume that the psychological construct MasculinityFemininity would constitute a central core of the character around which personality would be organized. The goal of this and other similar instruments would be to evaluate an individual's responses by comparing them to the characteristics of men and women, only maintaining the items that would significantly differentiate the sexes.

Anastasi (1982) referred three generations in the history of the development of the Masculinity and Femininity scales: the first generation would include the Attitude - Interest Test - M-Test by Terman and Miles (1936); in the second generation one would find the M-F subscale of the Minnesota Multiphasic Personality Inventory (MMPI) by Hathaway and McKingley (1943), the (M) of "Masculinity" subscale of the Guilford - Zimmerman Temperament Inventory (Guilford \& Zimmerman, 1949); and the "Femininity" subscale (FE) of the California Psychological Inventory (Gough, 1957). The third generation would include instruments more specifically dedicated to the isolated measurement of the constructs in question: the Bem Sex Role Inventory (BSRI) by Bem $(1974,1977)$, the Personal Attributes Questionnaire (PAQ) by Spence, Helmreich, and Stapp (as cited in Vieira, 2004), and the Sex-Role Behavior Scale (SRBS) by O'Heron and Orlofsky (1990).

The California Personality Inventory Femininity Scale (CPI-FE) (Gouch, 1957, 1975) would be a (limited) way to access aspects of gender behavior and feelings of the participants, whose (socially desirable) responses would evaluate their Masculinity/Femininity traits. An alternative to evaluate Masculinity/Femininity traits would be developed by Franck and Rosen (1949): the Franck Drawing Completion Test, which would employ a projective technique, less likely to value socially desirable answers.

Shepler (1951) would demonstrate a significant correlation between the Franck Test and three other testes (measuring different aspects of Masculinity/Femininity), namely the M scale of the Minnesota Multiphasic Personality Inventory (MMPI) and the Terman Miles-Attitude-Interest Analysis test. Barker, Mathis, and Powers (1953), Constantinople (1973), and Heilbrun (1976) 
criticized most tests aimed at evaluating traits of Masculinity - Femininity, insofar as these traits would not be unidimensional, measuring complex and heterogeneous factors. The CPI FE scale and the Draw-A-Person (DAP Test) (Whitkin et al., 1954) would be correlated with the degree of Feminine GI in male participants. These tests would seem to also measure different aspects of gender behavior in some individuals. The MMPI (Hathaway \& McKingley, 1943) would focus on a new scale: Masculinity/Femininity. A high score would always indicate a deviation of interests towards the opposite sex. A low score would mean exaggerated conformity with their sexual stereotype.

The subscales of the standard clinical scales of the MMPI did not initially include the scales of Masculinity/Femininity (MF) and Social Introversion (SI). Serkownek (1975) used the material from the factor analyses of the MF and SI scales (Graham, Schroeder, \& Lilly, 1971) to subdivide those two scales into subscales cited by Graham: (a) Masculinity - Femininity (MF): MF1 - Narcissism-Sensitivity, MF2 - Stereotypic Feminine Interests, MF3 - Denial of Stereotypic Masculine Interest, MF4 - Heterosexual Discomfort-Passivity, MF5 - IntrospectiveCritical, and MF6 - Socially Retiring; (b) Social Introversion (SI): SI1 - Inferiority-Personal Discomfort; SI2- Discomfort with Others; SI3 - Staid-Personal Rigidity; SI4 - Hypersensivity; SI5 - Distrust; and SI6 - Physical-Somatic Concerns (Graham, 1977 a, b).

The formal taxometric analysis of Sexual Orientation (Haslam, 1997) used the Masculinity/Femininity scale of the MMPI-2, MF, not showing that masculine sexual orientation was taxonomic. In Gangestad et al. (2000), there was evidence of a contrast with the results of Haslam (1997). They would conclude that this difference was due to the differences in the content of their evaluations and their MF subscales. The MF items were not explicitly in concordance with sexual orientation, child interests, or with GI.

Bem $(1974,1981,1985)$, in a review of a unifactorial gender model, would not see masculinity and femininity as opposite poles of a continuum (or negatively correlated constructs), rather viewing them as two independent dimensions, M-F. They would thus be schematized in a twodimensional space, as if they were two orthogonal factors (coexisting within it). Associated with this model would emerge a new instrument: the Bem Sex Role Inventory (BSRI) (Bem, $1974,1981)$ to separately evaluate masculinity and femininity, specifying another psychological construct: androgyny. According to Bem $(1974,1975)$, an androgynous individual would self-identify as competitive, independent, athletic, and simultaneously loyal, reserved, and understanding, in other words, with a balance between feminine and masculine results.

Bem (1977), taking into consideration the suggestions by Spence, Helmreich, and Stapp (1975), would develop their own evaluation method (BSRI), developing it into four types of personality: (a) sex-typed men would have above-average values of masculinity and belowaverage values of femininity; (b) non-sex-typed men would have above-average values of femininity and below-average values of masculinity; (c) androgynous individuals would be the men whose masculinity and femininity would both have above-average values; (d) the undifferentiated individuals would be the men whose masculinity and femininity would have below-average values.

Freund et al. (1982) would complement the study about the types of cross-GI with a clinical interview and a questionnaire containing seven scales: 1 - Andro; 2 - Gyno; 3 - Gender Identity (GI); 4 - Fetishism (Fe); 5 - Masochism (Maso); 6 - Sadism (Sad); 7 - Heterosexual Experience (Het. Exp.). From those results, they would focus on two hypotheses: 1 - with rare exceptions, some types of cross-GI would occur only in heterosexuals, others only in homosexuals; 2 - 
transsexualism would normally be accompanied or preceded by an anomaly in erotic preference. They would conclude that cross-GI, hetero or homosexual, would have different etiologies (no matter in what proportions their causes would be experiential or genetic).

Larsen and Seidman (1986) would present the psychometric properties of valid measurement constructs. The answers to the PRF Andro and the Bem Sex Role Inventory (BSRI) would be analyzed separately in sex-typed and non-sex-typed groups. The analysis of the several factors would illustrate structural theories of gender: (a) the factors of the sex-typed group would be bipolar. This would suggest that sex-typed individuals maintain a stereotyped bipolar opinion of the relationship between masculine and feminine traits. For the non-sex-typed group, the items of masculinity and femininity would tend to reside in both factors or in the same unidimensional factor. Therefore, in these individuals, masculine and feminine traits would not be opposite or mutually exclusive and the masculine/feminine dichotomy would be unimportant to the descriptions of their Self; (b) for the sex-typed group, biological sex would be linked in all factors of the BSRI and in three of four factors of the PRF Andro. This would suggest that the self-concepts of sex-typed individuals would be very well-defined by their biological sexes. For non-sex-typed individuals, biological sex would remain in only one of the factors. Thus, biological sex would not be a determining facet in their self-concepts.

In summary, sex-typed individuals would have the perception that the items of the SI scales would be filtered by a cognitive gender schema. The fact that the masculinity/femininity dichotomy does not appear in non-sex-typed gender responses would suggest that gender schema is not be correctly defined for this group.

Despite the popularity of the unifactorial models of the gender construct, substantial contents of differentiated gender characteristics and behaviors, including stereotypically masculine and feminine personality traits, would contribute to a simple bipolar dimension (Constantinople, 1973; Wakefield, Sasek, Friedman, \& Bowden, 1976; Orlofsky, 1981). This same material would also refuse a two-factor model, with masculine and feminine qualities constituting two orthogonal dimensions. However, for an increasing number of researchers, the gender construct would be multifactorial, in which the several factors would have little or no relationship with each other (Edwards \& Spence, 1987).

The Sex Role Identity Scale (SRIS; Storms, 1979) evaluates the global self-concept of personal Masculinity - Femininity. Women with high scores in assertive traits and low scores in expressive traits would be classified as less feminine in certain aspects. Nonetheless, they would not feel less adequate as women than those who assign themselves mainly feminine traits.

Gangestad et al. (2000) cite alternative evaluations of sexual orientation: Kinsey Scale of Sexual Attraction and Fantasy, Kinsey Scale of a Behavior Experience, and the Categorical Sexual Identity (that is, homosexual, bisexual, and heterosexual), in addition to the Gender Identity Scale for Males (Freund, Langevin, Satterber, \& Steiner, 1977) and the Masculine Gender Identity Scale (Blanchard \& Freund, 1985). All these scales would have a similar content, and they would relatively differ among homosexual and heterosexual individuals of the same sex.

As a critical focus of the evaluation methods, we would focus on the limitations of classifying self-perception of personality traits (or other sex-typed attributes): ( $1^{\text {st }}$ criticism) sex-typing would now be clearly multidimensional (Spence \& Hall, 1996; Spence \& Helmreich, 1980; Ruble \& Martin, 1998). Several people would exhibit only modest consistency, representing typically masculine or feminine behavior according to different domains (e.g., personality 
traits, preferences in relational or occupation activities, academic projects). It would thus be wrong to infer a GI predominantly through self-perception of sex-typing in any simple domain; ( $2^{\text {nd }}$ criticism) participants' self-classifications with specific gender-related attributes would question their non-perception of which attributes are relevant to gender. Focusing on what they would feel regarding gender categories, the $3^{\text {rd }}$ criticism on the motivational significance of the evaluation results would be applied here.

Bem (1981) suggested that people with: (a) high scores in instrumental traits and low scores in expressive traits, or (b) low scores in instrumental traits and high scores in expressive traits would be gender-typed, or motivated to adopt behavior consistent with one sex role and move away from behavior associated with the other (sex). Sex-typed self-perceptions would more likely reflect the pressure experienced to conform to the sex role rather than have another provenance (e.g., temperamental stimuli).

Multidimensional sex-typing would provoke changes in the GI theories. Would personal conceptions of gender-typing be nothing more than a heterogeneous placement of selfconcepts of specific sex-typed attributes, or would people somehow integrate their selfconcepts of the attributes to achieve esteem? Spence (1985) would suggest that a number of biological factors and social learning of gender-typing would interact to determine which specific sex-typed attributes an individual would develop. It would mainly be people with gender-typed feelings who would integrate themselves, in part due to their self-classifications into two adjectives - Masculine and Feminine. However, this recognition would also be influenced by the knowledge of their biological sexes.

Like Spence (1985), Egan and Perry (2001) argue that people would not only induce their selfconcepts in specific domains, but would also integrate various information about gender and the Self in order to achieve hierarchically superior symbolic components of GI. It would later be in terms of the integration of pleasure stimuli that personal judgment regarding gender would be built, in which affective strength would take its greater meaning in psychosocial adjustment (e.g., self-esteem and depression). As a main objective, Egan and Perry (2001) developed an evaluation of gender compatibility, the Self-Report Questionnaire, containing gender-typed selfconcept and gender satisfaction, and exploring two objectives: (1) they would test the hypotheses that the increase of gender compatibility would be beneficial for children's psychosocial adjustment (assessed in terms of self-worth, self-concept of social competence within the group and acceptance by the group). Theoretically, children would self-evaluate on the basis of gender compatibility (self-perception of gender-typing), experiencing discomfort or despair toward feelings of failure (Kohlberg, 1966; Spence \& Buckner, 1995), but also those with opposite-sex typing would experience anxiety, depression, and rejection by peers (Rekers, 1985; Bailey \& Zucker, 1995); (2) they would reveal the degree to which children feel compelled to the commitment of conducting themselves according to gender, experiencing strong pressure for sex typing, by their parents, peers, media, and other socializing agents, thus internalizing the prescribed messages and anticipating evaluative reactions from others and from themselves (Bem, 1981; Egan \& Perry, 2001). This self-limitation could promote a FalseSelf; (3) a third hypothesis of GI evaluation would be the Anti-Intergroup (the feeling that someone of their own sex would be superior to someone from the other), wherein the aim of the evaluation would be more the Group than the Self.

Thus, it is important to respect the multidimensionality of GI, and it would be an error to reduce it to a monolithic entity. 
Yunger, Carver, and Perry (2004) would formulate their evaluation systems: (1) Self-Concept Questionnaire to assess GI and Self-Esteem; (2) Peer Nomination Inventory, which would evaluate the perception of peer adjustment, and the (3) Sociometric Assessment, which would evaluate acceptance by peers.

Konik and Stewart (2004) developed an evaluation system containing demographic information and six questions about the topics of identity and sexual preferences, as well as the questionnaire Objective Measure of Ego-Identity Status (EOM - EIS) (Adams, Shea, \& Fitch, 1979; Adams, 1998). Accordingly, Konik and Stewart (2004) compared the analyses of categorical evaluations of SI, with those based on continuous assessments of sexual preference, obtaining similar results. A minority SI expressing sexual preferences for the same sex would be associated with higher levels of Achievement identity and lower levels of Foreclosure and Moratorium identities. Would the level of sexual preference for the same sex (not only the incorporation of some sexual preference of the same sex) currently be the predictive key to identity status?

\section{DISCUSSION}

Through theoretical contributions and by analyzing the behavior of individuals (parents, family, and small groups), the role of women would be highlighted in social interactions, maintenance of bonds and harmony within the family, and the typing of masculine behaviors in the orientation towards achieving goals, and exterior involvement. This distinction would originate two categories of personality attributes called Feminine Expressiveness, with characteristics of altruism, empathy, and tendency towards close interpersonal relationships, and Masculine Instrumentality, with aspects of dominance, competitiveness, and independence (Edwards \& Spence, 1987).

A third theoretical position for the development of Sexual Identification would be introduced by Kohlberg (1966), and would be linked to a cognitive development model, which recognizes the influence of parents as models in the development of sex roles, but also emphasizes the importance of the individual stage for the cognitive development in question, in order to understand people's point of view regarding their SI. More recently, there would be focus on the concept of androgyny, which would introduce the terms Agency and Communion to represent the masculine and feminine aspects of personality. Agency would refer to that part of experience that is individual (experienced only by the Self), and Communion would refer to collective experience (experienced together with others). Some authors would combine the concepts of Agency and Communion with sexual stereotypes of masculinity and femininity, to define the components of SI (Bem, 1974; Spence, Helmreich, \& Stapp, 1975; Berzins, Welling, \& Weller, 1978). Block (1973) would propose parallel stages of Development of Sexual Identification and Ego Development, and it would be implicit in this model that the former is a trait of a more global facet of the latter.

Based on the literature on Ego Development (Costos, 1986), it would be expected that higher levels would be associated with orientations androgynous in their sex role, whereas the lower levels would be associated with sex-typed orientations. Therefore, in the most evolved stages, the conceptual conflict would be discovered and there would be emergence of interest in the sex role, openness regarding sex-role stereotypes, and ability to expand themselves in masculine and feminine possibilities. The fact the person carries in themselves a replica of another sex as a psychological potentiality, and according to Heinich (1996), would not in any way suppress recognition of the differentiation of the sexes. It would be the absence or insufficiency of such a replica that would prohibit or change it. Bisexuality would be a source of paradoxes or of the notions of foreignness of others, as well as the access to the foreign, 
allowing to refuse the unconscious assimilation of change, opposition or, at least, to temper the consequences. In other words, "love in its means is war: in its foundation it is the mortal hatred of the sexes" (Nietzsche).

Bem (1974) has suggested a fourth classification of Undifferentiated applied to individuals that obtain low scores in both dimensions. Spence, Helmreich, and Stapp (1975) adopted this classification to characterize individuals with low scores in masculinity and femininity within the validity of the Personal Attributes Questionnaire (PAQ). In this construct, individuals who display high scores in both dimensions would be androgynous. Empirically, in this last classification, individuals would be more intelligent, creative, and more socially adapted (Spence, Helmreich, \& Holahan, 1974), more flexible in terms of behavior, and would exhibit greater self-esteem in psychological terms (Bem, 1985). Given the lack of empirical support for the theory proposed by Bem $(1981,1983)$, Spence $(1985,1993,1999)$ would propose a new conceptualization of gender as being multifactorial, as it is not possible to bring together all behavioral components of masculinity and femininity under one sole factor (Terman \& Miles, 1936), in which the psychological construct referred to as Masculinity - Femininity would constitute the central trait of temperament around which personality would organize itself, or two (Bem, 1985, 1998). According to Vieira (2004), the aspects that would contribute to the differentiation of each integrating factor of gender would contain idiosynchromatic stories of development, always different from individual to individual, which are influenced by a multiplicity of variables not necessarily related to gender. Such factors could also exhibit different degrees of association among themselves in each period of life, with masculine and feminine behavior being a result of the complex interaction of their various components that should not be understood as independent of each other (though not presupposing an orthogonal nature because of this), since according to this multidimensional perspective, it would be expected that individuals' results in unifactorial instruments, conceived to measure specific aspects related to gender, could exhibit positive correlations between them. Thus, it would be possible to observe intra and intersex variability in the constellation of characteristics congruent with gender. Nevertheless, this does not mean that individuals would feel undecided about their identity, as members of one or another sexual category. Green (1974) would argue that most men and women would be able to develop, from the earliest years of their childhood, a clear sense of belonging to their sexual category, which would remain stable throughout life.

In conclusion, currently, conceptions of masculinity/femininity (and androgyny) would be outdated if we considered that they referred to gender stereotypes, just as the behavioral differences observed between the sexes, which would provoke their emergence, would lead to the furthering of research on the topic. The results of experiments could be observed from different perspectives, such as their implications for theories about masculinity and femininity and gender structuring.

Traditionally, it would be presumed that the observable qualitative differences of gender differentiation would interrelate, so that one could not only be predicted through the other, but could also use any classification, such as Instrumental and Expressive traits, as diagnostic indicators of a simple underlying sector. However, from theoretical consultation of literature on the subject, questions concerning these assumptions would be added, suggesting that the qualities of gender differentiation would be structurally multifactorial. These finding would lead some authors to develop a GI theory that incorporates this multidimensionality.

In the experiments discussed above, evidence of gender structuring in connection with personality traits was found. 
Without denying the influence of Biology and Sociology, it would be important to think that men and women have similar repertoires for gender role representation, but their expectations on how they should behave would lead them to take into play scripts for selectively differentiated relational interaction. In other words, and according to Poeschl, Múrias, and Ribeiro (2003), if socialization shapes personality to match gender role expectations, in turn, these expectations would limit them to stereotyped behavior.

By focusing on gender structuring, sex role evaluations and gender stereotypes, we would find the same disadvantage, and we cannot ignore the possibility that they would substitute individual differences in each person's gender sensibility and could be more strongly manifested under other conditions. Thus, the concepts of Masculinity and Femininity would refer to fundamental psychological qualities, which, together with physical characteristics, would be at the core of being a man or a woman. Given this conviction, it appears that paths to future research remain open.

\section{References}

Adams, G. (1998). Objective measure of ego identity status: A reference manual. Guelph, Ontario: University of Guelph.

Adams, G., Shea, J., \& Fitch, S. (1979). Toward the development of an objective assessment of ego-identity status. Journal of Youth and Adolescence, 8, 223-237.

Althof, S. (2000). Erectile dysfunction: Psychotherapy with men and couples. In S. R. Leiblum \& R. C. Rosen (Eds.). Principles and practices of sex therapy (pp. 242-275). New York: Guilford.

American Psychiatric Association. (2013). Diagnostic and Statistical Manual of Mental Disorders (Fifth ed.). Arlington, VA: American Psychiatric Publishing.

Anastasi, A. (1982). Psychological Testing. New York: The Macmillan Company.

Andersen, L., \& Cyranowski, M., (1995). Women's Sexuality. Behaviors, Responses and Individual Differences. Journal of Consulting and Clinical Psychology, 63(6), 891-906.

Angelides, S. (2001). A History of Bisexuality. Archives of Sexual Behavior, 33(2), 170-172.

Badinter, E. (1992). XY On Masculine Identity. Lisboa: Asa Editora.

Bailey, J., \& Zucker, K. (1995). Childhood sex-typed behavior and sexual orientation: A conceptual analysis and quantitative review. Developmental Psychology, 31, 43-55.

Barker, J., Mathis, J., \& Powers, C. (1953). Drawing characteristics of male homosexuals. Journal of Clinical Psychology, 9, 185-188.

Barnett, M. (1960). Vaginal awareness in the infancy and childhood of girls. Journal of the American Psychoanalytic Association, 14, 129-141.

Bégoin, J. (2000). A Adolescência: Descoberta e Integração da Identidade Sexual. Revista da Sociedade Portuguesa de Psicanálise, 20, 3-16.

Bem, S. (1974). The measurement of psychological androgyny. Journal of Consulting and Clinical Psychology. 42 , 155-162.

Bem, S. (1975). Sex role adaptability: One consequence of psychological androgyny. Journal of Personality and Social Psychology, 31, 634-643.

Bem, S. (1977). On the utility of alternative procedures for assessing psychological androgyny. Journal of Consulting and Clinical Psychology, 45, 196-205.

Bem, S. (1981a). Gender schema theory: A cognitive account of sex typing. Psychological Review, 88, 354-364.

Bem, S. (1983). Gender schema theory and its implications for child development: Raising gender-aschematic children in a gender-schematic society. Signs, 8, 598-617.

Bem, S. (1985). Androgyny and gender schema theory: A conceptual and empirical integration. In T.B. Sonderegger (Ed.). Nebraska Symposium of Motivation: Psychology and gender (pp. 179-226). Lincoln: University of Nebraska Press. 
Bem, S. (1998). Gender schema theory and its implications for child development: Raising gender-aschematic children in a gender-schematic society. In D. Anselni \& A. Law (Eds.). Questions of Gender: Perspectives and Peradoses (pp. 262-274). New York: McGraw-Hill.

Berzins, J., Welling, M., \& Weller, F. (1978). A new measure of psychological androgyny based on the personality research form. Journal of Consulting and Clinical Psychology, 46, 126-136.

Bettelheim, B. (1954). Symbolic. Wounds Glencoe, III: Free Press.

Biller, H. (1976). The father and personality development: Paternal deprivation and sex role development. In M. Lamb (Ed.) The role of the father in child development (pp. 319-358). New York: Wiley.

Blanchard, R., \& Freund, K. (1985). Measuring masculine gender identity in females. Journal of Consulting and Clinical Psychology, 51, 205-214.

Block, J. (1973). Conceptions of sex role. Some cross cultural and longitudinal perspectives. American Psychologist, 28, 512-526.

Bower, H. (2001). The Gender Identity Disorder in the DSM-IV Classification: A Critical Evaluation. Australian \& New Zealand Journal of Psychiatry, 35(1), 1-8.

Bronson,W. (1959). Dimensions of ego infantile identification. Journal of Personality, 27, 532-545.

Campo, J., Nijman, H., Merckelbach, H., \& Evers, C. (2003). Psychiatric Comorbidity of Gender Identity Disorders: A Survey among Dutch Psychiatrists. American Journal of Psychiatry, 160(7), 1332-1336.

Cass, V. (1979). Homosexual identity formation: A theoretical model. Journal of Homosexuality, 4, 219- 235.

Chodorow, N. (1974). Family structure and feminine personality. In M. Z. Rosaldo \& L. Lamphere (Eds.), Women, culture and society (pp. 43-66). Stanford. CA: Stanford University Press.

Coleman, E. (1982). Development stages of the coming-out process. American Behavior Scientist, 25, 477.

Constantinople, A. (1973). Masculinity-femininity: An exception to the famous dictum? Psychological Bulletin, 80, 389-407.

Costos, D. (1986). Sex Role Identity in Young Adults: Its Parental Antecedents and Relation to Ego Development. Journal of Personality and Social Psychology, 50(3), 602-611.

David, C. (1975). Présentation du Rapport: La Bissexualité Psychique: Eléments d'une Réévaluation. Revue Française de Psychanalyse XXXVéme, XXXIX, 695-803.

Davis, D. (1998). The Sexual and Gender Identity Disorders. Transcultural Psychiatry Special Issue: Culture in DSM-IV, 35(3), 401-412.

Douvan, E. (1960). Sex difference in adolescent character processes. Merril Palmer Quarterly, 6 203-211.

Edwards, V., \& Spence, J. (1987). Gender-related traits, stereotypes and schemata. Journal of Personality and Social Psychology, 53, 146-154.

Egan, S., \& Perry, D. (2001). Gender Identity: A Multidimensional Analysis with Implications for Psychosocial Adjustment. Developmental Psychology, 37(4), 451-463.

Erikson, E. (1968). Identity, Youth and Crisis. New York: W.W. Norton \& Company, Inc.

Foucalt, M. (1994). História da Sexualidade I. A Vontade de Saber. Lisboa: Relógio de Água.

Fraiberg, S. (1972). Some characteristics of genital arousal and discharge in latency girls. The Psychoanalytic Study of the Child, 27, 439-475.

Franck, K., \& Rosen, E. A. (1949). A projective test of masculinity-femininity. Journal of Consulting Psychology, 13, 247-256.

Freud, S. (1905). Three Essays on the Theory of Sexuality. Madrid: Editorial Biblioteca Nueva.

Freud, S. (1908). Hysterical Phanthasys and their Relation to Bisexuality. Madrid: Editorial Biblioteca Nueva.

Freud, S. (1915). Instincts and their Vicissitudes. Madrid: Editorial Biblioteca Nueva.

Freud, S. (1917). Introductory Lectures on Psycho-Analysis. Madrid: Editorial Biblioteca Nueva.

Freud, S. (1920). Beyond the Pleasure Principle. Madrid: Editorial Biblioteca Nueva.

Freud, S. (1923). The Ego and the Id. Madrid: Editorial Biblioteca Nueva. 
Freund, K., Langevin, R, Satterberg, J., \& Steiner, B. (1977). Extension of the Gender Identity Scale for Males. Archives of Sexual Behavior, 6, 507-519.

Freund, K., Steiner, B., \& Chan, S. (1982). Two Types of Cross-Gender Identity. Archives of Sexual Behavior, 11(1), 49-63.

Gangestad, S., Bailey, J., \& Martin, N. (2000). Taxometric Analysis of Sexual Orientation and Gender Identity. Journal of Personality and Social Psychology, 78(6), 1109-1121.

Gough, H. (1957). Manual for the California Psychological Inventory. Palo Alto, CA: Consulting Psychologists Press. Gough, H. (1975). Manual for the California Psychological Inventory. Palo Alto, CA: Consulting Psychologists Press. Graham, J. (1977a). The MMPI: A Practical Guide. New York: Oxford University Press.

Graham, J. (1977b). Review of Minnesota Multiphasic Personality Inventory Special Scales. In Advances in Psychological Assessment. Volume 4. Paul McReynolds (Ed.). San Francisco: Jossey-Bass Publishers.

Graham, J., Schroeder, H. E., \& Lilly, R. (1971). Factor analysis of items on the social introversion and masculinityfemininity scales of the MMPI. Journal of Clinical Psychology, 27, 367-370.

Green, R. (1974). Sexual identity conflict in children and adults. New York: Basic Books.

Greenson, R. (1968). Dis-identifying from the mother: its special importance for the boy. The International Journal of Psychoanalysis, 49, 370-374.

Grotevant, H. (1992). Assigned and chosen identity components: A process perspective on their integration. In G. R. Adams, T. P. Gullotta, \& R. Montemayor (Eds.). Adolescent identity formation (pp. 73-190). Thousand Oaks, CA: Sage.

Guilford, J., \& Zimmerman, W. (1949). The Guilford-Zimmerman Temperament Survey: Manual of instruction and interpretation. Beverly Hills, CA: Sheridan Supply Co.

Harris, J. (1995). Where is the child's environment? A group socialization theory of development. Psychological Review, 102, 458-489.

Haslam, N. (1997). Evidence that male sexual orientation in a matter of degree. Journal of Personality and Social Psychology, 73, 862-870.

Hathaway, R., \& Mckinley, J. (1943). Minnesota Multiphasic Personality Inventory Minneapolis. EUA: University of Minnesota Press.

Heilbrun, A. (1976). Identification with the father and sex role development of the daughter. Family Coordinator, $25,411-416$.

Heinich, N. (1996). Estados da mulher. A identificação feminina na ficção ocidental. Lisboa: Editorial Estampa, Lda. Hetherington, E. (1965). A development study of effects of sex of the dominant parent on sex role preference, identification, and imitation in children. Journal of Consulting and Clinical Psychology, 44, 843-851.

Irvine, J. (1995). Sexuality education across cultures. Scarborough, Ontario: Jossey-Bass.

Jung, C. (1959). The archetypes of the collective unconscious: The collected works of CG. University of Minnesota: Pantheon Books.

Jung. (1971). Psychological types: The collected works of CG. University of Minnesota: Pantheon Books.

Kagan, J. (1964). Acquisition and significance of sex typing and sex role identity. In M.L. Hoffman \& L.W. Hoffman (Eds.), Review of child development research (Vol. 1, pp. 137-168). New York: Russel Sage Foundation.

Kelly, J., \& Worell, L. (1976). Parent behaviors related to masculine, feminine and androgynous sex role orientations. Journal of Consulting and Clinical Psychology, 44, 843-851.

Kestenberg, J. (1968). Outside and inside male and female. Journal of the American Psychoanalytic Association, 16, 457-520.

Klein, A. (1993). Little big men: Bodybuilding subculture and gender construction. New York: State University of New York.

Klonsky, D., Serrita, J., Turkheimer, E., \& Oltmanns, T. (2002). Gender Role and Personality Disorders. Journal of Personality Disorders, 6(5), 464-476.

Kohlberg, L. (1966). A cognitive-developmental analysis of children sex-role concepts and attitudes. In E.E. Maccoby (Ed.) The development of sex differences pp. 82-173). Stanford, CA: Stanford University Press. 
Konik, J., \& Stewart, A. (2004). Sexual Identity Development in the Context of Compulsory Heterosexuality. Journal of Personality, 72(4), 815-844.

Kubie, L. (1974). The drive to become both sexes. Psychoanalytic, 43, 349-426.

Lacan, J. (1966). Ècrits, Paris: Editions du Seuil.

Larsen, R., \& Seidman, E. (1986). Gender Schema Theory and Sex Role Inventories: Some Conceptual and Psychometric Considerations. Journal of Personality and Social Psychology, 50(1), 205-211.

Lynn, D. (1976). Fathers and sex role development. Family Coordinator, 25, 403-409.

Maccoby, E. (1998). The two sexes. Growing up apart, coming together. Cambridge MA: Harvard University Press.

Moulton, R., Liberty, P. Jr., Burnstein, E., \& Altucher, N. (1966). Patterning of parental affection and disciplinary dominance as a determinant of guilt and sex typing. Journal of Personality and Social Psychology, 4, 356-363.

National Science Foundation (1996). Women, minorities, and persons with disabilities in science and engineering: 1996 (National Science Foundation Publication No. 96-311). Arlington, VA: Author.

Nosek, B., Banaji, M., \& Greenwald, A. (2002). Math = Male, ME = Female, Therefore Math $\neq$ ME. Journal of Personality and Social Psychology, 83(1), 44-59.

O’Heron, C., \& Orlofsky, J. (1990). Stereotypic and Nonstereotypic Sex Role Trait and Behavior Orientations, Gender Stöller Identity, and Psychological Adjustment. Journal of Personality and Social Psychology, 58(1), 134143.

Orlofsky, J. (1979). Parental antecedents sex role orientation in college men and women. Sex Roles, 5, 495-512.

Orlofsky, J. (1981). Relationship between sex-role attitudes and personality traits and the Sex- Role Behavior Scale-1: A new measure interests. Journal of Personality and Social Psychology, 40, 927-940.

Pleck, J. (1975). Masculinity-femininity. Current and alternative paradigms. Sex Roles, I, 161-178.

Pleck, J. (1977). The psychology of sex roles: Traditional and new views. In L. A. Cater, A. F. Scott, \& Martine (Eds.). Women and men: Changing roles, relationships, and perception (pp. 181-199). New York: Praeger.

Poeschl, G., Múrias, C., \& Ribeiro, R. (2003). As Diferenças entre os Sexos: Mito ou Realidade?. Análise Psicológica, 2(XXI), 213-228.

Rekers, G. (1972). Pathological sex-role development in boys: Behavioral treatment and assessment. Doctoral dissertation, University of California, Los Angeles. Ann Arbor, MI: University Microfilms.

Rekers, G. (1975). Stimulus control over sex-typed play in cross-gender identified boys. Journal of Experimental Child Psychology, 20, 136-148.

Rekers, G. (1977). Assessment and treatment of childhood gender problems. In B.B. Lahey \& A. E. Kazdin (Eds.), Advances in clinical child psychology, Volume I (pp. 267-306). New York: Plenum Press.

Rekers, G. (1985). Gender identity problems. In P. A. Bornstein \& A. E. Kazdin (Eds.), Handbook of clinical behavior therapy with children (pp.. 658-699). Homewood, IL: Dorsey Press.

Rienzi, B., Forquera, J., \& Hitchock, D. (1995). Gender Stereotypes for Proposed D.S.M.-IV Negativistic, Depressive, Narcissistic, and Dependent Personality Disorders. Journal of Personality Disorders, 9(1), 49-55.

Rosenfeld, H. (1971). A Clinical Approach to the Psychoanalytic Theory of Life and Death Instincts: An Investigation into the Aggressive of Narcissism. International Journal of Psychoanalysis, 52, 169-178.

Rouart, J. (1975). Narcisse et la Bisexualité Psychique ou le Suspens Narcissique. Revue Française de Psychanalyse, 5(6), 993-1012.

Rubinstein, G. (2003). Macho Man: Narcissism, Homophobia, Agency, Communion, and Authoritarianism - A Comparative Study among Israeli Bodybuilders and a Control Group. Psychology of Men \& Masculinity, 4(2), 100110.

Ruble, D., \& Martin, C. (1998). Gender development. In N. Eisenberg, (Ed.), Handbook of childpsychology: Social, emotional, and personality development (pp. 933-1016). New York: Wiley.

Serkownek, K. (1975). Subscales for Scales 5 and 0 of the MMPI. Unpublished Manuscript.

Shepler, B. (1951). A comparison of masculinity-femininity measures. Journal of Consulting Psychology, 15, 484486.

Silverman, A. (1986). La Identificacion en la Formacion Saludable y Patologica del Carácter. Libro Anual de Psicoanálisis, 103-112. 
Spence, J. (1984a). Gender identity and its implications for the concepts of masculinity and femininity. Nebraska Symposium on Motivation, 32, 59-96.

Spence, J. (1984b). Masculinity, femininity and gender-related traits: A conceptual analysis and critique of current research. Progress in Experimental Personality Research, 1, 1-97.

Spence, J. (1985). Gender identity and its implications for the concepts of masculinity and femininity. In T.B. Sonderegger (Ed.). Nebraska symposium on motivation: Psychology and Gender (Vol. 32, pp. 59-95). Lincoln: University of Nebraska Press.

Spence, J. (1993). Gender-related traits and gender ideology: evidence for a multifactorial theory. Journal of Personality and Social Psychology, 64, 624-635.

Spence, J. (1999). Thirty years of gender research: A personal chronicle. In W. B. Swann, J. H. Langlois \& Gilbert, L. A. (Eds.). Sexism and stereotypes in modern society. The gender science of Janet Taylor Spence, (pp. 255-289). Washington: American Psychological Association.

Spence, J., \& Buckner, C. (1995). Masculinity and femininity: Defining the undefinable. In P. J. Kalbfleisch \& M. J. Cody (Eds.), Gender, power, and, communication in human relationships (pp. 105-138). Hillsdale, NJ: Eribaum.

Spence, J., \& Hall, S. (1996). Children's gender-related self-perception, activity preferences, and occupational stereotypes: A test of three models of gender constructs. Sex Roles, 35, 659-691.

Spence, J., \& Helmreich, R. (1978). Masculinity and femininity: Their psychological dimensions, correlates, and antecedents. Austin: University of Texas Press.

Spence, J., \& Helmreich, R. (1980). Masculine instrumentality and feminine expressiveness: their relationships with sex role attitudes and behaviors. Psychology of Women Quarterly 5(2), 147-163.

Spence, J., Helmreich, R., \& Holaban, C. (1979). Negative and positive components of psychological masculinity and femininity and their relationships to neurotic behavior. Journal of Personality and Social Psychology, 37, 1673-1682.

Spence, J., Helmreich, R., \& Stapp, J. (1975). Ratings of self and peers on sex role attributes and their relations to self-esteem and conceptions of masculinity and femininity. Journal of Personality and Social Psychology, 32, 2939.

Stöller, R. (1968). Sex and Gender. New York: Aronson.

Stöller, R. (1975). Sex and Gender. The transsexual Experiment. New York: Aronson.

Stöller, R. (1984). Sex and Gender. The development of masculinity and femininity. Maresfield Library: Karnac Books.

Storms, M. (1979). Sex role identity and relationships to sex role attributes and sex role stereotypes. Journal of Personality and Social Psychology, 37, 1779-1789.

Terman, L., \& Miles, C. (1936). Sex and personality: Studies in masculinity and femininity. New York: McGraw Hill. Tiefer, L. (1995). Sex is not a natural act. Boulder, CO: Westview.

Torok, M. (1979). The significance of penis envy woman. In J. Chasseguet-Smirgel (ed.), Female Sexuality Ann Arbor. Univ. of Michigan Press.

Vieira, C. (2004). Empirical Studies Implications of the Male and Female Characteristics: Masculinity, Femininity and Androgyny. Psychologica, 623-633.

Wakefield, J. Jr, Sasek, J., Friedman, A., \& Bowden, J. (1976). Androgyny and other measures of masculinityfemininity. Journal of Consulting and Clinical Pathology, 44, 766-660.

Weinberg, G. (1972). Society and the healthy homosexual. New York: St. Martin's Press.

White, K., \& Speisman, J. (1977). Adolescence. Monterey, CA: Brooks/Cole.

Whitkin, H., Lewis, H., Hertzman, M., Machover, K., Bretnall-Meissner, P., \& Wagner, S. (1954). Personality through perception - an experimental and clinical study. New York: Harper \& Brothers.

Yarhouse, M. (2001). Sexual Identity Development: The Influence of Valuative Frameworks on Identity Synthesis. Psychotherapy: Theory, Research, Practice, Training, 38(3), 331-341.

Yunger, J., Carver, P., \& Perry, D. (2004). Does Gender Identity Influence Children's Psychological Well - Being?. Developmental Psychology, 40(4), 572-582. 